\title{
Um fio vermelho em Franz Kafka
}

\section{Enrique Mandelbaum}

$\mathrm{E}$ M MAIO de 1924, Kafka agonizava, dilacerado por uma tuberculose que provocava lesões na garganta tão sérias que a respiração, a fala e a deglutição estavam seriamente comprometidas. Sua aparência física materializava uma agonia na qual se tornava quase impossível encontrar a esperança de vencer a morte. Aos 41 anos, kafkianamente, Kafka morria de fome, realizando um incrível esforço para revisar as provas tipográficas de seu texto Um artista da fome. No dia 2 de junho, a agonia atingia o nível do insuportável. Ele pede ao seu médico: "Mate-me, senão você é um assassino". Finalmente, numa terça-feira, 3 de junho, ao meiodia, Kafka morre. Morre mas não desaparece. A partir daí, uma literatura que se estima em mais de vinte mil títulos, sem contar as centenas de milhares de páginas nunca publicadas de autores anônimos e as incalculáveis reflexões que sua pequena obra escrita desperta em cada um de seus leitores, é posta em movimento, com uma intensidade tão enérgica que nada indica que virá a se esgotar.

Enquanto os homens enfrentarem as mazelas do dia-a-dia urbano, do mundo organizado do qual nunca mais se espera que eles saiam, Kafka estará presente como um outdoor afixado permanentemente numa das vias principais, próximo do olhar de toda a multidão anônima que por ali circula. Kafka é daqueles poucos autores cuja obra transborda os textos e se transforma em parte do cenário das vidas humanas, ressoando em todas as dimensões das situações dos homens. Toda organização estatal de qualquer país do mundo tem algo de kafkiano. Toda instituição, pública ou privada, religiosa, acadêmica ou mafiosa, midiática, beneficente, esportiva, social ou o que seja tem algo de kafkiano em seu interior. Toda casa, toda vida em família reserva, em seus aposentos, um nicho kafkiano. Toda fala entre os homens, toda comunicação acolhe também tanto a demanda por um entendimento quanto o mal-entendido, e ambos podem ser kafkianos. Enfim, todo homem guarda em seu interior uma estranheza de si consigo próprio que é também kafkiana. Kafka penetra tão fundo a vida que é capaz de se instalar em compartimentos e lugares do acontecer humano tão raros que poucos autores, para não dizer nenhum outro, conseguem lhe fazer companhia.

Entre as letras e a vida humana, o espaço é difícil de ser encurtado e não existe nenhuma trilha fácil, nenhum atalho facilitador. Por isso, é bom desconfiar de toda escrita e, antes de mais nada, desconfiar de nós próprios. Dostoiévski disse: "O homem é um patife - e patife é aquele que diz sê-lo", incluindo a si próprio como uma voz portadora da qualidade de patife, para despertar em seus leitores uma desconfiança que não se reduza à relação com os outros e com o mundo que os rodeia, mas que inclua antes a eles próprios, fazendo de cada um alguém desconfiado de si mesmo.

Kafka é herdeiro dessa tradição que visa levar os homens a desconfiarem de si próprios, exacerbando-a ao máximo, a ponto de que ela incida sobre o próprio texto que realiza (não devemos esquecer sua séria demanda de que sua obra escri- 
ta fosse queimada após a sua morte). E é essa ampliação da desconfiança por sobre todo o campo textual que levou muitos de seus primeiros críticos a verem em seus escritos algo assim como uma ruína do trabalho literário, a representação de um declínio contextualizado historicamente: os escritos de Kafka como porta-vozes das impossibilidades burguesas para responder com positividade às demandas históricas que exigiriam a superação da própria burguesia. $\mathrm{Ou}$ ainda o registro das impossibilidades do homem diante do acúmulo de insucessos história adentro. Porém, mesmo os críticos mais inquietos com o estado de coisas realizado por Kafka reconhecem em suas obras a presença de um grande escritor. E principalmente a realização de um enigma que nunca se fecha plenamente, porque nele, apesar de tanta negatividade, apesar de tanta desconfiança, o homem ainda se ergue por inteiro.

Michael Löwy, em Franz Kafka, sonhador insubmisso, recolhe um Kafka que poria em atividade, em seu trabalho literário, um enorme desejo de liberdade e uma extrema sensibilidade para com a violência promovida pelas fontes de poder arbitrárias, que se deslocariam como que em ondas sísmicas desde um epicentro do poder do pai sobre os filhos às instâncias burocráticas do estado autoritário, e que o levariam a criar uma obra literária na qual todo o estado de coisas é considerado "desde o ponto de vista de suas vítimas”. Löwy propõe-se a acompanhar com cuidado e atenção o que ele chama de um "fio vermelho" presente nos textos kafkianos, por meio de uma leitura que ele nomeia "sociopolítica" e que lhe permite apontar o conteúdo antiautoritário da escrita kafkiana. E o faz como um autor acostumado ao diálogo polêmico com outros críticos, e como um experimentado investigador de textos das ciências políticas e sociais. Sua pesquisa fixa um Kafka que flerta simpaticamente com idéias libertárias, fazendo das experiências do escritor com leituras e personagens anarquistas uma das evidências de suas convicções pessoais, que atuariam com profundidade ao longo de toda a sua obra. É verdade que, em Kafka, as organizações sociopolíticas e culturais são responsáveis, em grande medida, pelo sofrimento dos homens, mas esse sofrimento, a nosso ver, não se reduz em seus escritos apenas a um produto do entorno, não provém exclusivamente do estranhamento e da hostilidade do mundo exterior. Ethos e Cosmos se integram, mas um não se dilui no outro. Em Kafka, um agulhão de estranhamento parece estar implantado nas próprias entranhas de cada homem e impede a possibilidade de uma síntese pessoal estabilizadora.

Löwy, porém, deixa de lado, nesse estudo, essa dimensão da obra kafkiana, privilegiando uma leitura que responsabiliza as estruturas burocratizadas do poder pelo sofrimento e a alienação dos homens, e promove assim uma redução da complexidade kafkiana, na qual, como no relato $A$ colônia penal, a violência se inscreve como letra no corpo humano e faz de cada um não apenas uma vítima, mas também um sujeito capaz de suscitá-la. Essa é a gravidade do universo kafkiano: cada um, mesmo aquele que mais sofre, pode ser um agente violento. Essa é a situação kafkiana por excelência, na qual todos atropelam todos e todos são atropelados pela máquina burocrática que é posta em atividade.

Um dos intuitos centrais da leitura de Löwy é tentar evidenciar quais seriam 


\section{Michael Löwy} FRANZKAFKA
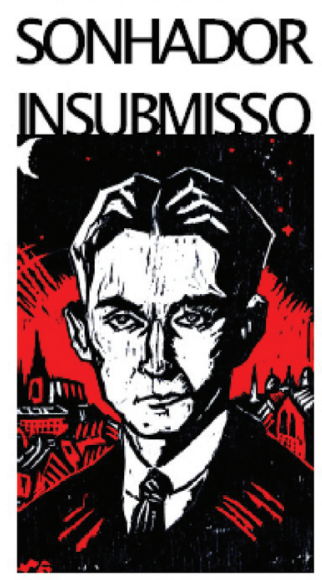

a

LÖWY, M. Franz Kafka, sonbador insubmisso. Trad. Gabriel Cohn. Rio de Janeiro: Azougue Editorial, 2005.

as motivações e as fontes de inspiração do trabalho literário de Kafka. Assim, por exemplo, ele sustenta que $A$ colônia penal teria como origem uma crítica de Kafka ao colonialismo, ao militarismo e à burocracia, chegando até a argumentar em favor de um colonialismo bem específico - o colonialismo francês - que estaria na mira da crítica de Kafka, e Löwy hesita entre saber se o espaço territorial em que se passa o relato seria a Ilha do Diabo, "para onde o Capitão Dreyfuss havia sido remetido após sua condenação, mas lá não havia população indígena", ou a Nova Caledônia, "essa 'colônia penal' francesa habitada por melanésios, para onde foram deportados os prisioneiros communards, mas Kafka não menciona prisioneiros deportados, políticos ou outros" (p.83). Para O processo, Löwy põe em cena a hipótese de que processos anti-semitas teriam sido a sua fonte, ou ainda que a irmã Otla seria o modelo arquetípico sobre o qual teria sido construída a personagem Amália, da novela $O$ castelo.

O diálogo entre realidade e obra literária nunca é fácil, e a crítica contemporânea há muito abriu mão de ver a literatura como cópia do real. Löwy, porém, aponta para cada obra uma origem na realidade social, da qual a obra seria um desdobramento imaginativo. Que em toda obra literária uma determinada ideologia se materialize numa ação imaginária é inquestionável. Ocorre que o caso de Kafka é emblemático de uma literatura que, para além de querer representar um estado de coisas da vida dos homens, toma a si própria como o problema a ser trabalhado. E Löwy parece, nesse trabalho, pouco atento a esse fato. Ao priorizar a apresentação de um Kafka antiautoritário, ele termina por filtrar aspectos importantes do texto kafkiano, principalmente no que diz respeito a questões referentes à forma da escrita, lugar por excelência da singularidade de que o texto de Kafka é dotado. Löwy privilegia uma crítica suportada sobre o que seria o argumento do texto. Mas o trabalho literário consiste basicamente na operação textual que é realizada, isto é, nos artifícios de escrita que o escritor põe em cena, selecionando cada palavra, construindo cada oração, atento à estrutura frasal, e assim por diante. E isso mais ainda em Kafka, um autor que operava consciente de sua atividade textual e crítico dela, atuando não por meio da linguagem mas na linguagem, lugar em que está alocada, pela forma como Kafka opera, grande parte das tensões constitutivas de seu texto. E Löwy, em seu filtro crítico, muitas vezes termina por privar o texto kafkiano dessa tensão, o que significa, de algum modo, privar a letra do "espírito kafkiano" (a expressão é de Löwy). 
Isso não quer dizer que a leitura de Löwy não seja de grande valia. Ao contrário, ela contribui em muito para destacar um Kafka que é também um genial leitor crítico do estado de coisas entre os homens. E isso não é pouco diante de um panorama da crítica literária contemporânea, que muitas vezes tende a encerrar a obra literária num compartimento estético-lingüístico, destituindo a obra de toda a sua potência crítica. E o próprio Löwy sabe dos limites de seu trabalho, quando escreve:

a leitura "política" proposta aqui evidentemente é parcial: o universo de Kafka é rico, complexo e multiforme demais para ser redutível a uma fórmula única. Seja qual for a pertinência de uma interpretação, sua obra guarda todo o seu inquietante mistério, sua singular consistência onírica como um "sonho desperto", inspirado pela lógica do maravilhoso. (p.13)

Se toda leitura de Kafka é parcial, se nenhuma a esgota, por que então o enorme esforço de Löwy para se colocar como original dentro do gigantesco campo crítico desse autor? Ele diz: “em lugar algum encontrei uma análise sistemática de sua obra pelo ângulo da paixão anti-autoritária que a atravessa como uma corrente elétrica” (p.12). Não é o caso de trazer aqui o incrível leque de críticos que assentam sua leitura de Kafka justamente nessa "paixão antiautoritária”. Citemos apenas Canetti (1981, p.146). Diz ele: "Desde um princípio, Kafka foi partidário dos humilhados". E referindo-se a $O$ castelo: "Nunca se escreveu um ataque mais claro contra a submissão ao que é superior, tanto se queremos entender por isto um poder divino ou meramente terreno". É importante salientar que toda a leitura de
Canetti desdobra esse pensamento em profundidade, bem como as de Benjamin, Adorno, Ritchie Robertson, Hannah Arendt, Marthe Robert, Deleuze e Guatarri e tantos outros que o próprio Löwy cita. Porém, se Löwy não é o primeiro a vê-la por esse ângulo, esse volume tem o mérito indiscutível de iluminar em que medida essa paixão antiautoritária percorre a obra kafkiana em sua totalidade, situando-a no contexto da realidade européia da primeira metade do século XX.

Referência bibliográfica

CANETTI, E. El otro proceso de Kafka. Barcelona: Muchnik Editores, 1981.

Enrique Mandelbaum é psicanalista, educador e autor de Franz Kafka: um judaismo na ponte do impossível (Perspectiva, 2002). @- eimande@terra.com.br 